\title{
Determination of the intrinsic permeability to water of cementitious materials: Influence of the water retention curve
}

\author{
Stéphane Poyet \\ CEA, DEN, DPC, SECR, Laboratoire d'Etude du Comportement des Bétons et des Argiles, F-91191 Gif sur Yvette, France
}

\section{A R T I C L E I N F O}

\section{Article history:}

Received 22 April 2011

Received in revised form 23 August 2012

Accepted 26 August 2012

Available online 5 September 2012

\section{Keywords:}

Concrete

Water transport

Permeability

Desorption isotherm

Mualem-van Genuchten model

\begin{abstract}
A B S T R A C T
Water transport is a key issue for concrete structures durability; the most important parameter may be the intrinsic permeability to water. It is usually estimated through inverse analysis on the basis of the experimental weight loss of concrete samples in a controlled environment. By doing so, Mualem's model together with van Genuchten's equation are used to describe the water retention curve as well as the relative permeability evolution. To study the influence of such a restriction, the intrinsic permeability of a modern concrete was estimated using different mathematical expressions to describe the water retention curve. A simple numerical procedure was set up to approximate the relative permeability evolution according to Mualem's model. The results show that the intrinsic permeability depends on the model used whereas all the effective permeability evolutions tend to describe the same evolution. It is believed that in this evaluation process the obtained intrinsic permeability to water is not a fully relevant parameter for the effective permeability evolution.
\end{abstract}

(c) 2012 Elsevier Ltd. All rights reserved.

\section{Introduction}

The durability of concrete structures is greatly influenced by the amount of free water present [8]. By free water it is meant water that is not chemically bound and is free to evaporate; it involves capillary and adsorbed water [18]. This influence is well illustrated by the well-known results of Tuutti [25] which show the important evolution of the corrosion current of steel embedded in a carbonated mortar as a function of the external relative humidity $(\mathrm{RH})$. In a more general way, water significantly influences concrete behavior (for instance through shrinkage and creep that can result in cracking) and durability (through transport properties and inhibition of in-solution chemical reactions). A reliable durability assessment of concrete structures in relation to their environment thus requires an accurate description of water transport all along their service life.

Water transport within porous media involves permeation of both liquid and gaseous (mix of vapor and dry air) phases and diffusion of vapor within the gaseous phase. The neat description of these phenomena results in a complex set of three coupled differential equations; see for instance [7,21,13,5,14]. The major drawback of such a description is the very large number of input data which are almost impossible to acquire experimentally.

From a practical point of view, water transport in cementitious materials is usually described in a simplified way using a single

E-mail address: stephane.poyet@cea.fr equation which accounts for liquid water permeation only: the other motions (vapor diffusion as well as gaseous permeation) are neglected. This assumption was found to be true for weakly permeable materials: it is the case for a concrete with an intrinsic permeability to water equal to $10^{-21} \mathrm{~m}^{2}$ [13]. Note that Coussy required the intrinsic permeability to be much lower than $10^{-19} \mathrm{~m}^{2}$ [5]. Recently, Thiery and coworkers [23,24] estimated the respective contribution of each motion for three different concretes. They showed that the assumption validity depends on the intrinsic permeability and the $\mathrm{RH}$-domain considered. For instance for a high-performance concrete with low permeability $\left(\approx 2 \times 10^{-22} \mathrm{~m}^{2}\right)$ the assumption appears to be true between $\mathrm{RH}=20 \%$ and $100 \%$ whereas for a low-strength concrete with high permeability $\left(\approx 4 \times 10^{-19} \mathrm{~m}^{2}\right)$ the validity domain is limited to $65-100 \% \mathrm{RH}$.

To describe water transport in a simplified way, one must start from the extension of Darcy's law for unsaturated flow [19] which gives the water mass flux $j_{w}$ :

$j_{w}=-\rho \frac{K k_{r}}{\eta} \operatorname{grad}(P)$

where $P$ is the liquid pressure [Pa]; $\eta$ and $\rho$ the water viscosity [Pa s] and density $\left[\mathrm{kg} / \mathrm{m}^{3}\right.$ ] respectively; $K$ is the intrinsic permeability to water, it characterizes the resistance of the saturated concrete to water flow (under a pressure gradient) $\left[\mathrm{m}^{2}\right]$ and $k_{r}$ is the relative permeability to water [without unit], it describes the influence of 
water content on permeability. It ranges between 0 (dry state) and 1 (saturated state). The mass conservation equation writes:

$\frac{\partial}{\partial t}(\rho \phi S)=-\operatorname{div}\left(j_{w}\right)$

where $S$ is the saturation index [without unit], it describes how pores are filled with liquid water: it ranges between 0 (dry state) and 1 (saturated state) and $\phi$ is the concrete porosity [without unit]. In isothermal conditions, assuming that water is incompressible and that there exists a unique and differentiable relation between saturation $S$ and water pressure $P$ (this relation is known as the capillary-pressure curve) one can easily obtain the following equation:

$\phi\left(\frac{\partial S}{\partial P}\right) \frac{\partial P}{\partial t}=\operatorname{div}\left[\frac{K k_{r}}{\eta} \operatorname{grad}(P)\right]$

The simplified description of water transport within concrete thus requires the knowledge of four physical parameters; namely porosity $\phi$, capillary-pressure curve $S=S(P)$, intrinsic and relative permeability to water $K$ and $k_{r}$. The porosity $\phi$ can be very easily and quickly measured by complete drying of initially saturated samples. The capillary-pressure curve is more difficult to acquire experimentally: it is generally obtained by submitting concrete samples to different RHs (in isothermal conditions) and waiting for equilibrium (that is to say constant weight) [2]. The RH at equilibrium is then converted into water pressure $P$ using KelvinLaplace equation:

$P=-\rho \frac{R T}{M} \operatorname{Ln}(h)$

where $T$ is the absolute temperature [K], $R$ the universal gas constant $[\mathrm{J} / \mathrm{mol} / \mathrm{K}], M$ is the water molar mass $[\mathrm{kg} / \mathrm{mol}]$ and $h$ is the relative humidity. The intrinsic permeability to water $K$ is almost always deduced through an inverse analysis using experimental mass loss $[1,13]$. In so doing, the relative permeability to water $k_{r}$ is always estimated using the model proposed by Mualem [15]. It is based on the description of the interconnected pore distribution and it creates a link between the capillary-pressure curve and the relative permeability evolution. Once the capillary-pressure $S=S(P)$ curve is known, the relative permeability can be estimated in an integral form:

$k_{r}(S)=S^{\alpha}\left[\frac{\int_{0}^{S} \frac{1}{P(u)} d u}{\int_{0}^{1} \frac{1}{P(u)} d u}\right]^{2}$

where $\alpha$ is the pore-interaction factor, it describes the effect of the pore-distribution connectivity. It is taken equal to 0.5 as a default value as proposed by Mualem [15]. This model is likely to be the most reliable and accurate model for predicting the relative permeability evolution. However, this expression is not easy to handle since the pressure $P$ tends towards 0 when the saturation $S$ tends towards 1 . As a consequence, an analytical expression for the relative permeability cannot be derived, unless the equation proposed by van Genuchten is used [26]:

$S(P)=\left[1+\left(\frac{P}{P_{0}}\right)^{n}\right]^{-m}$

where $P_{0}, m$ and $n$ are three-parameters to be fitted on the experimental capillary-pressure curve. $P_{0}$ is equivalent to a pressure [Pa] whereas $m$ and $n$ are two positive exponents. When implemented into Mualem's model together with the restriction $m=1-\frac{1}{n}$ an analytical expression can be derived (the parameter $m$ is the same in all equations):

$k_{r}(S)=S^{\alpha}\left[1-\left(1-S^{\frac{1}{m}}\right)^{m}\right]^{2}$

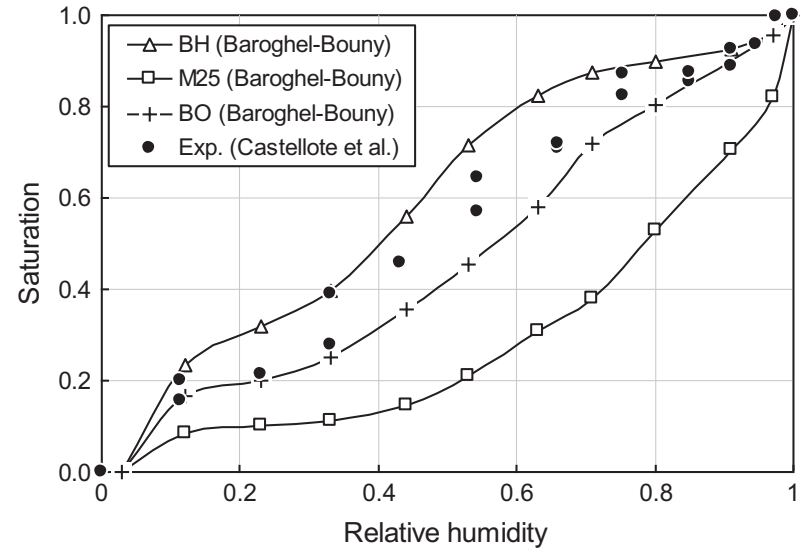

Fig. 1. Comparison between the desorption isotherm of the considered concrete [4] and the reference results of [2].

$k_{r}(S)=\left[1+\left(\frac{P}{P_{0}}\right)^{\frac{1}{1-m}}\right]^{-m \alpha}\left(1-\left(\frac{P}{P_{0}}\right)^{-\frac{m}{1-m}}\left[1+\left(\frac{P}{P_{0}}\right)^{\frac{1}{1-m}}\right]^{-m}\right)^{2}$

Eq. (7) recalls the classical form of the relative permeability given by van Gencuhten (as a function of saturation $S$ ) whereas Eq (8) presents the expression which is of interest in this study (as a function of water pressure $P$ ). In the same way, the van Genuchten's isotherm allows the analytical estimation of the left-hand term from Eq. (3):

$\phi\left(\frac{\partial S}{\partial P}\right)=-\frac{m \phi}{(m-1) P_{0}}\left(\frac{P}{P_{0}}\right)^{\frac{m}{1-m}}\left[1+\left(\frac{P}{P_{0}}\right)^{\frac{1}{1-m}}\right]^{-1-m}$

The equation proposed by van Genuchten is widely used and has proven its great flexibility in describing experimental results for soils [27]. It was also proven to be suitable for cementitious materials [20]. Yet in the author's mind the obliged use of the van Genuchten model appears as a major limitation of this approach. It can be imagined that in some cases van Genuchten's equation does not fit well the experimental results. One can then wonder about the impact of such a wrong description on the permeability estimation. To answer to this question, the intrinsic permeability of a modern concrete was evaluated on the basis of an isothermal drying experiment and different water retention curve models were used in the process.

\section{Experimental program}

\subsection{Material data}

The material considered in this study is a modern concrete designed and studied by ONDRAF-NIRAS ${ }^{1}$ (the Belgian agency for radioactive waste and enriched fissile materials) in the framework of a Low-Level Waste disposal project in Belgium (for concrete containers) [16]. It is based on European CEM I (Ordinary Portland Cement) and the water-to-cement ratio is equal to 0.47 . The superplasticizer content was adjusted so that the slump would reach $15 \mathrm{~cm}$. The average compressive strength at 28 days is equal to $49 \mathrm{MPa}$ using cylinders (60 MPa was obtained using cubes).

A large experimental campaign was undertaken at the Eduardo Torroja Institute (IeTcc ${ }^{2}$ ) in which many characterization tests were conducted [4]. Among all of them the first desorption isotherm was acquired. Initially saturated concrete disks $(\varnothing 5 \times 0.5 \mathrm{~cm})$ were

\footnotetext{
${ }^{1}$ http://www.nirond.be/.

2 http://www.ietcc.csic.es/.
} 
Table 1

Composition of the considered concrete.

\begin{tabular}{llll}
\hline Compound & Nature & Quantity & Unit \\
\hline Cement & CEM I 42.5 & 350 & $\mathrm{~kg} / \mathrm{m}^{3}$ \\
Sand $(0-4 \mathrm{~mm})$ & Limestone & 686 & $\mathrm{~kg} / \mathrm{m}^{3}$ \\
$\begin{array}{l}\text { Aggregate } \\
\quad \text { Calcareous }\end{array}$ & 1128 & $\mathrm{~kg} / \mathrm{m}^{3}$ \\
$\begin{array}{l}\text { Filler } \\
\text { Water }\end{array}$ & Ground calcium carbonate & 50 & $\mathrm{~kg} / \mathrm{m}^{3}$ \\
Superplasticizer & BASF RheoBuild 1100 & 164.5 & $\mathrm{~L} / \mathrm{m}^{3}$ \\
& & 8.7 & $\mathrm{~mL} / \mathrm{kg}$ of cement \\
\hline
\end{tabular}

exposed to different RHs using saturated salt solutions. The experiment was conducted at $21^{\circ} \mathrm{C}$ and drying at $105^{\circ} \mathrm{C}$ was chosen for the reference dry state. The resulting isotherm is depicted in Fig. 1 (plain circles) and compared to three reference results obtained by Baroghel-Bouny $[2]^{3}$ : a high-performance concrete (denoted "BH", $w / c=0.27$ ); an ordinary concrete ("BO", $w / c=0.49$ ) and a lowstrength concrete ("M25", w/c $=0.84$ ). As it can be expected the isotherm obtained for the considered concrete is very similar to the ones of the ordinary and high-performances concretes (see Table 1).

\subsection{Isothermal drying test}

In order to evaluate the intrinsic permeability to water, an isothermal drying test was undertaken. Five prismatic concrete specimens $(15 \times 15 \times 15 \mathrm{~cm})$ cast in industrial conditions (taken during the fabrication of concrete container prototypes) were provided to CEA by ONDRAF/NIRAS and were then kept under water at $20^{\circ} \mathrm{C}$ for 3 months. Two cylinders $(\varnothing 6 \mathrm{~cm})$ were cored out of each specimen. The properties of both top and bottom ends are known to differ from the ones of rest of the specimen [12,9,10,11]; they were then cut off (about 1-2 cm) and discarded. The 10 resulting cylindrical samples $(\varnothing 6 \times 11.5 \mathrm{~cm})$ were believed to present homogenous properties, but it was not verified anyhow. The sample dimensions are big enough (compared to the aggregate maximal diameter) to ensure representativeness. The initial properties (volume, mass) were determined using hydrostatic weighing and the cylindrical samples $(\varnothing 6 \times 11.5 \mathrm{~cm})$. No special procedure was undertaken to achieve full saturation of the samples before hydrostatic weighing. According to our experience, keeping concrete specimens under water is far enough to ensure full saturation after a 3-month curing period. Each sample was weighed under water in an air-conditioned room $\left(20 \pm 1^{\circ} \mathrm{C}\right)$. After the water in excess on the sample surface was removed with a wet cloth, each sample was weighed in open air using the same weighing device. The obtained results (volume $\approx 0.32 \mathrm{~L}$ and mass $\approx 0.77 \mathrm{~kg}$ ) allowed calculating the saturated density values (Table 2 ).

The ten-sample set was put in a climatic chamber at $20^{\circ} \mathrm{C}$ and $54 \% \mathrm{RH}$. These conditions were chosen because they were thought to be representative of the climatic conditions to be expected at the disposal location. The chamber was opened periodically, the samples were weighed and their relative mass variation was computed. They were submitted to drying for 2 months (of course, this period was not long enough to reach equilibrium). After the drying test, the samples were completely dried at $105^{\circ} \mathrm{C}$ (until constant weight) to have their porosity computed (see Table 2 ). Fig. 2 presents the evolution of the sample relative mass variation all along the drying test (for clarity the drying at $105^{\circ} \mathrm{C}$ is not reported).

\footnotetext{
${ }^{3}$ The results obtained by Baroghel-Bouny et al. were chosen as a reference because the isotherm results were complemented by Thiery and coworkers with the evaluation of the intrinsic permeability to water (using the same methodology as presented in this article)
}

Table 2

Properties of the 10 cored samples.

\begin{tabular}{lll}
\hline Sample & Saturated density $\left(\mathrm{kg} / \mathrm{m}^{3}\right)$ & Porosity $(\%)$ \\
\hline 1 & 2463 & 12.1 \\
2 & 2427 & 11.5 \\
3 & 2448 & 11.4 \\
4 & 2447 & 11.7 \\
5 & 2453 & 11.3 \\
6 & 2476 & 11.6 \\
7 & 2476 & 11.5 \\
8 & 2461 & 12.0 \\
9 & 2466 & 11.8 \\
10 & 2463 & 11.4 \\
Average & 2458 & 11.6 \\
\hline
\end{tabular}

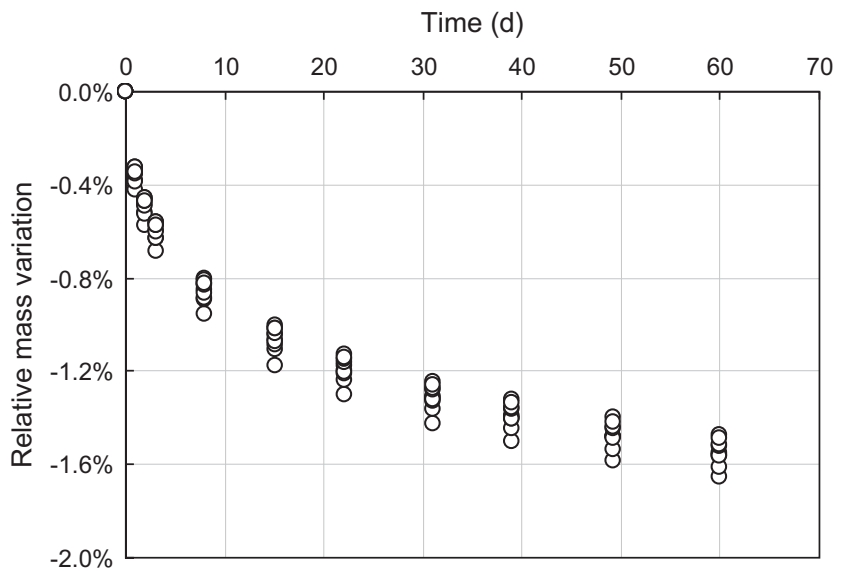

Fig. 2. Relative mass variation of the ten concrete samples during the drying test $\left(20^{\circ} \mathrm{C}\right.$ and $\left.54 \% \mathrm{RH}\right)$.

Table 3

Van Genuchten parameters obtained in this study and fitted on the results of Baroghel-Bouny [2] by Thiery et al. [23].

\begin{tabular}{lclllll}
\hline van Genuchten parameters & This study & {$[23,2]$} & \multirow{2}{*}{ Unit } \\
\cline { 3 - 5 } & & $\mathrm{BH}$ & $\mathrm{BO}$ & $\mathrm{M} 25$ & \\
\hline Pressure $P_{0}$ & 59.05 & 106.6 & 35.4 & 13.1 & MPa \\
Exponent $m$ & 0.532 & 0.640 & 0.417 & 0.437 & - \\
\hline
\end{tabular}

\section{Permeability evaluation using Mualem-van Genuchten models}

\subsection{Conventional approach}

The usual methodology was briefly presented in the introduction. First of all, the parameters $P_{0}$ and $m$ of (Eq. (6)) were fitted to reproduce the experimental water retention curve. The values obtained are reported in Table 3. They are compared to the reference results obtained by Baroghel-Bouny [2] and Thiery et al. [23]. As observed above, the parameters obtained are between the ones of the ordinary and the high-strength concretes. Fig. 3 depicts the comparison, between the experimental data and the fitted isotherm: the description is quite good aside from the RH-interval $80-100 \%$ for which the saturation is (slightly) overestimated. This point is addressed later.

Eq. (3) is solved using the finite-element method [28] and the code Cast $3 \mathrm{~m}$ that is developed by $\mathrm{CEA}^{4}$. The left- and right-hand

\footnotetext{
${ }^{4}$ For more detail, the readers are referred to the website: http://wwwcast3m.cea.fr.
} 


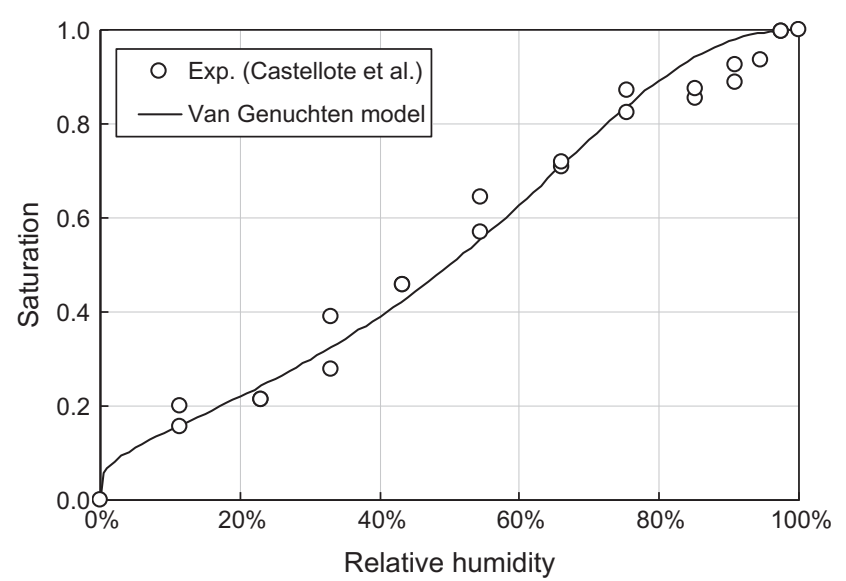

Fig. 3. Description of the experimental desorption isotherm using the equation proposed by van Genuchten $\left(P_{0}=59.05 \mathrm{MPa}, m=0.532\right)$.

terms are calculated using Eqs. (9) and (8) respectively. In accordance with the symmetry of the problem, the mesh only accounts for a sample quarter in axisymmetric conditions (Fig. 4): $80 \times 160$ four-node quadrangles (QUA4, linear elements) were used in a uniform grid. The initial conditions are uniform temperature $T_{0}=293.15 \mathrm{~K}$ and water pressure $P_{0}=0.0 \mathrm{MPa}$ (the samples are initially saturated). The boundary conditions are (for time $\geqslant 0$ ): $T=293.15 \mathrm{~K}$ and $P=-83.3 \mathrm{MPa}$ (corresponding to $\mathrm{RH}=54 \%$ ).

An example of numerical restitution (solid lines) of the experimental relative mass variation (circles) is presented in Fig. 5 for five different values of the intrinsic permeability $K$ $\left(1.0 ; 1.5 ; 2.0 ; 3.0\right.$ and $5.0 \times 10^{-22} \mathrm{~m}^{2}$ from top to bottom, respectively). The intrinsic permeability which fits the best the results appears to be ranging from 1.5 to $3.0 \times 10^{-22} \mathrm{~m}^{2}$; and $2.0 \times 10^{-22} \mathrm{~m}^{2}$ seems to be very close to the optimal value.

In order to have an objective and accurate evaluation procedure, the intrinsic permeability was estimated by minimization of the quadratic difference between the computed (superscript sim) and measured (superscript exp) relative mass variations for each time:

$F=\sum_{i=1}^{N}\left[\left(\frac{\Delta m}{m}\right)_{i}^{\exp }-\left(\frac{\Delta m}{m}\right)_{i}^{\operatorname{sim}}\right]^{2}$

where $N$ is the number of mass measurements (10 in our case). Note that by doing so, the average experimental relative mass variation is considered. The evolution of the objective function $F$ is displayed in

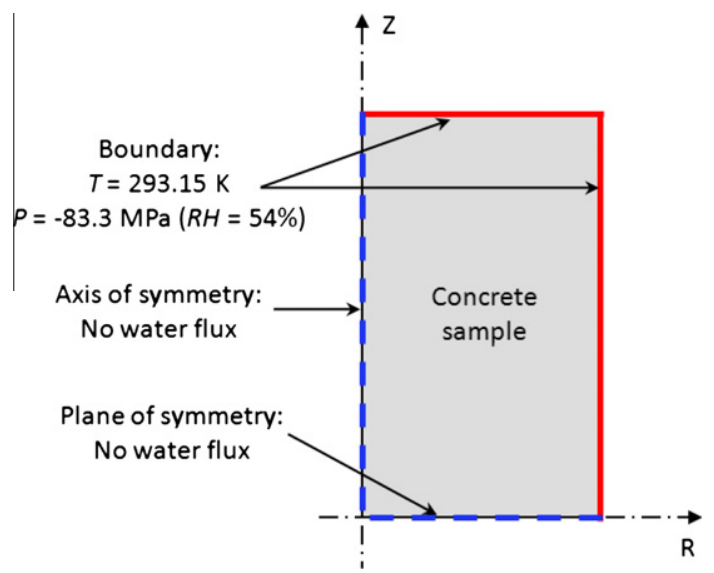

Fig. 4. Schematic description of the mesh and boundary conditions used.

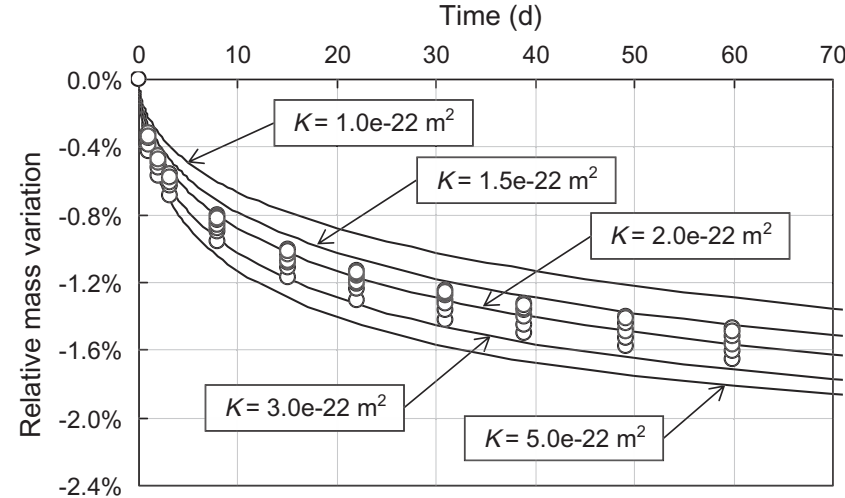

Fig. 5. Numerical restitution of the relative mass variation as a function of the intrinsic permeability $K$.

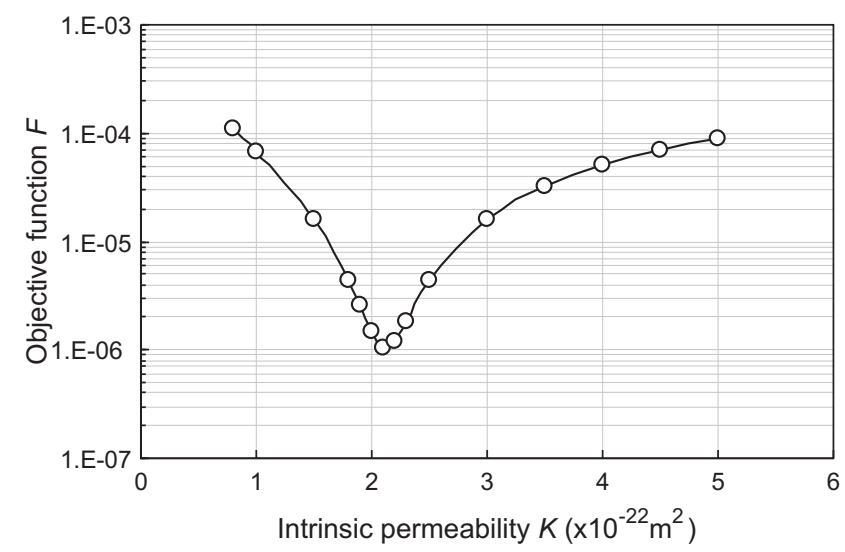

Fig. 6. Evolution of the quadratic deviation $F$ as a function of the intrinsic permeability $K$.

Fig. 6. The minimum gives the value of the intrinsic permeability to water: $2.1 \times 10^{-22} \mathrm{~m}^{2}$.

The evolution of the resulting effective permeability (that is to say the product of the relative and intrinsic permeabilities) of the considered concrete is presented in Fig. 7. Are also presented the evolutions obtained by Thiery et al. [23] reprocessing in the same way as in this article the results of Baroghel-Bouny [2]. The permeability evolution of the considered concrete is very similar to the one of the high-performance concrete $(\mathrm{BH})$. The difference of slope between the two curves is due to the difference in the exponent $m$ from Eq. (6) (Table 3).

\subsection{Three-parameter van Genuchten model}

It should be noted in Fig. 3 that the van Genuchten model does not fit well the results between $80 \%$ and $100 \% \mathrm{RH}$. If one wants to improve the isotherm description, one must try to use the threeparameter van Genuchten model. It was proposed by van Genuchten and Nielsen [27] as an alternative to van Genuchten original model [26] to yield a better description of soils water retention curves. The model equation is exactly the same as the original (Eq. (6)) but the difference lies in the absence of restriction on the values of the parameters $m$ and $n$; that is to say they are independent. The resulting model uses three-parameters (instead of two) to fit the experimental capillary-pressure curve. When the three-parameter model is used in association with Mualem's model an analytical derivation of the relative permeability can also be done but the resulting equation is more difficult to handle [27]: 


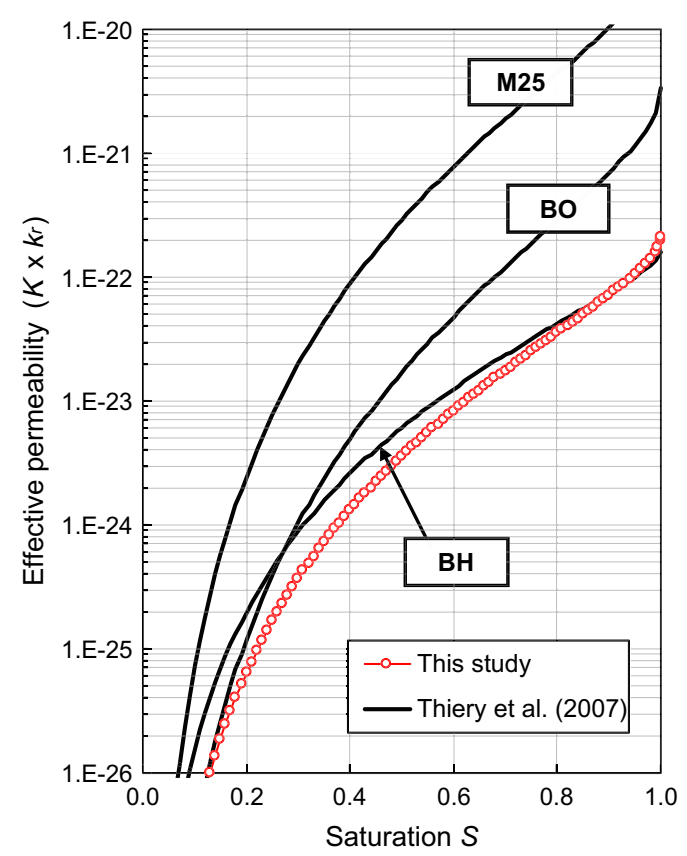

Fig. 7. Evolution of the effective permeability of the considered concrete as estimated using the usual van Genuchten model and comparison with results taken from literature $[23,2]$.

$$
\left\{\begin{array}{l}
k_{r}(P)=\left[1+\left(\frac{P}{P_{0}}\right)^{n}\right]^{-m \alpha} I_{\xi}\left(m+\frac{1}{n} ; m-\frac{1}{n}\right) \\
\text { with } \xi=\frac{1}{1+\left(\frac{P}{P_{0}}\right)^{n}}
\end{array}\right.
$$

where $I_{\xi}$ is the incomplete Beta function [6], its values are tabulated or can be found in mathematics codes or in most spreadsheets. The intrinsic permeability was estimated through the process detailed above (the same mesh was used). The left-hand term of Eq. (3) is easy to calculate:

$\phi\left(\frac{\partial S}{\partial P}\right)=-\frac{m \phi}{(m-1) P_{0}}\left(\frac{P}{P_{0}}\right)^{n-1}\left[1+\left(\frac{P}{P_{0}}\right)^{n}\right]^{-1-m}$

The parameters for the three-parameter model are listed in Table 4. Fig. 8 presents the evolution of the isotherm described using the three-parameter van Genuchten (solid line) and the comparison with the original model (dotted line). The new description is closer to the experimental results between $80 \%$ and $100 \% \mathrm{RH}$ but the improvement is not very convincing since the new curve is very close to the original. Accordingly, the permeability obtained $\left(2.7 \times 10^{-22} \mathrm{~m}^{2}\right)$ is also very close to the value obtained using the usual van Genuchten model $\left(2.1 \times 10^{-22} \mathrm{~m}^{2}\right)$.

\section{Alternative methodology}

\subsection{Approximation procedure for the relative permeability}

As quoted in the introduction the model proposed by Mualem can only be used together with the van Genuchten isotherm equa-

Table 4

Values for the three-parameter van Genuchten model.

\begin{tabular}{lll}
\hline van Genuchten parameters & This study & Unit \\
\hline Pressure $P_{0}$ & 76.39 & MPa \\
Exponent $m$ & 0.752 & - \\
Exponent $n$ & 1.770 & - \\
\hline
\end{tabular}

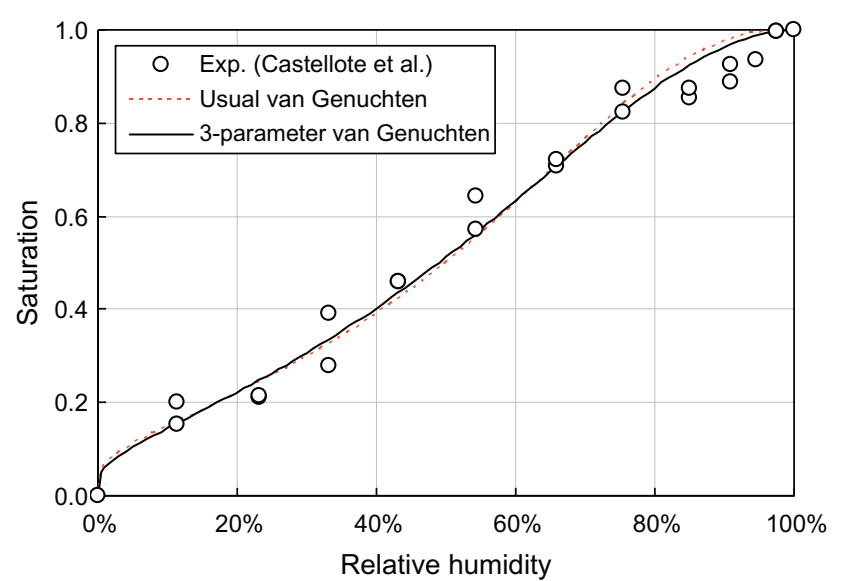

Fig. 8. Description of the experimental capillary-pressure curve using the threeparameter van Genuchten model (solid line); comparison with the usual model (dotted line).

tions (the usual or the three-parameter) to derive a simple analytical formula for the relative permeability. This explains the wideuse of the Mualem-van Genuchten equations for the description of water transport in porous media. If one wants to use any other arbitrary mathematical equation, one must find a way to solve Eq. (5). In this study, it was decided to approximate the integrals from Eq. (5) using the trapezoidal form of Riemann sums (note that Mualem used a numerical approximation scheme to evaluate relative permeability evolutions). The trapezoidal rule consists in approximating the surface area under a curve by a composition of trapezoids. From a practical point of view, to estimate the integral $\int_{a}^{b} f(x) d x$ one must decompose the interval $[a, b]$ into $N$ uniform elements and sum the surface area of each trapezoid. This writes:

$\int_{a}^{b} f(x) d x \approx \frac{1}{2 N}[f(a)+f(b)]+\frac{1}{N} \sum_{k=1}^{N-1} f\left(a+k \frac{b-a}{N}\right)$

In our case, $x$ corresponds to saturation $S, f(x)$ to the capillary-pressure inverse $\frac{1}{P(S)}$ and the saturation interval of interest is [0,1]. Note that for $S=0$, the capillary-pressure tends to infinity $\left(\frac{1}{P(S)} \rightarrow 0\right)$. In order to manage the indetermination at $S=1\left(\frac{1}{P(S)} \rightarrow \infty\right)$, the last trapezoid surface area (that is to say the one with one side at $S=1$ ) was omitted in the summation process: the denominator of Eq. (5) then writes:

$\int_{0}^{1} \frac{1}{P(u)} d u \approx \frac{1}{2 N P\left(\frac{N-1}{N}\right)}+\frac{1}{N} \sum_{k=1}^{N-2} \frac{1}{P\left(\frac{k}{N}\right)}$

Using the same methodology (and the same interval subdivision) the numerator can be written as follows:

$\left\{\begin{array}{l}\int_{0}^{S} \frac{1}{P(u)} d u \approx \frac{1}{2 N P\left(\frac{N}{N}\right)}+\frac{1}{N} \sum_{k=1}^{\mathscr{N}} \frac{1}{P\left(\frac{k}{N}\right)} \\ \text { where } \quad N \in \mathbb{N}^{*+}, S=\frac{\mathcal{N}}{N} \text { and } \mathscr{N} \leqslant(N-1)\end{array}\right.$

The relative permeability to water can then be approximated using the following equation:

$k_{r} \approx\left(\frac{\mathscr{N}}{N}\right)^{\alpha}\left[\frac{\frac{1}{2 N P\left(\frac{N-1}{N}\right)}+\frac{1}{N} \sum_{k=1}^{N-2} \frac{1}{P\left(\frac{k}{N}\right)}}{\frac{1}{2 N P\left(\frac{\mathscr{N}}{N}\right)}+\frac{1}{N} \sum_{k=1}^{\mathscr{N}-1} \frac{1}{P\left(\frac{k}{N}\right)}}\right]^{2}$

For validation purpose, the usual van Genuchten relative permeability evolution (Eq. (6), with the usual restriction $m=1-\frac{1}{n}$ ) was 
estimated using the approximation procedure (Eq. (16)) described above and then compared to the analytical solution (Eq. (7)). The results are presented in Fig. 9 for three different values of $N$ (100, 1000 and 10,000$)$.

For these three values, from $k_{r}=10^{-4}$ to 1 , the results follow the line of equality $(y=x)$ indicating that the trapezoidal rule accurately describes the relative permeability evolution on this interval. Below $k_{r}=10^{-4}$ the results deviate from the line of equality (the approximation procedure underestimates the relative permeability). The point of deviation $\left(k_{r}=10^{-4}\right)$ approximately corresponds to $S \approx 0.2$; that is to say $\mathrm{RH} \approx 20 \%$. This value is far below the minimal $\mathrm{RH}$ used in the isothermal drying experiment used in this study $(\mathrm{RH}=54 \%)$ : approximated evolutions can then be used with confidence to describe the isothermal drying experiment. Increasing the number of subintervals is helpful in improving the convergence of the approximation process; yet $N=1000$ appeared to the writer as the best compromise between accuracy and complexity of the description. This value was then used further onto estimate the relative permeability evolution for other isotherm functions. From a practical point of view, to improve the convergence of the approximation scheme, one could in a first increase the number of subintervals or use non-uniform subdivisions.

\subsection{Application to other isotherm models}

\subsubsection{Linear model}

In a first time, a straight line was used to describe the experimental isotherm in the simplest way:

$S(h)=a+b h$

The values of the two constants $a$ and $b$ are equal to 0.053 and 0.947 respectively. Fig. 10 compares the resulting line to the experimental results. The description is quite good despite the simplicity of the model. The left-hand term of Eq. (3) is very easy to obtain:

$\phi\left(\frac{\partial S}{\partial P}\right)=-\frac{M}{\rho R T} b \phi \exp \left(-\frac{M P}{\rho R T}\right)$

The relative permeability evolution $k_{r}$ was approximated using the procedure detailed above and the intrinsic permeability to water was fitted to mimic the experimental mass variation (Fig. 2). The value obtained is equal to $2.0 \times 10^{-21} \mathrm{~m}^{2}$; it is one order of magnitude higher than the values obtained using the usual van Genuchten model.

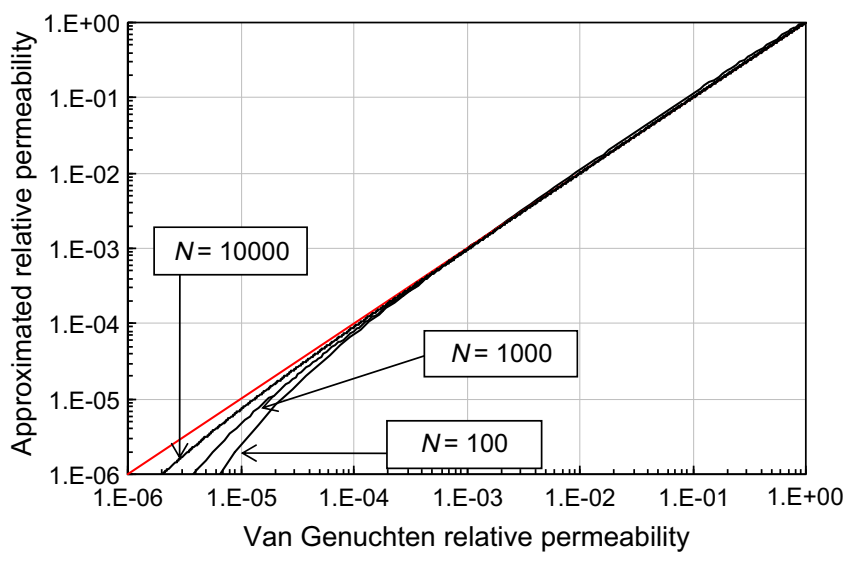

Fig. 9. Comparison between the relative permeability evolutions predicted using the Mualem-van Genuchten analytical equation and the trapezoidal rule.

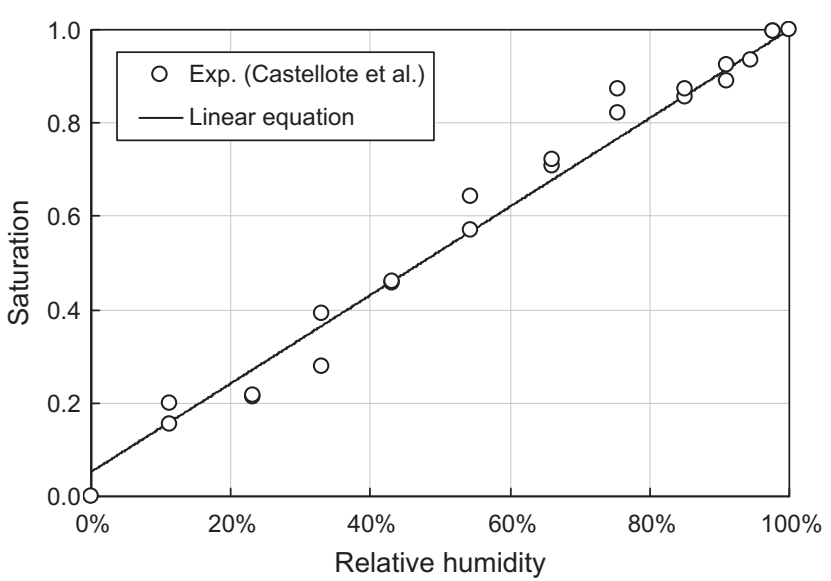

Fig. 10. Description of the experimental desorption isotherm using a straight line.

\subsubsection{Polynomial function}

A polynomial equation (of order 6) was also used:

$S(h)=\sum_{k=0}^{6} a_{k} h^{k}$

Fig. 11 presents the comparison between the experiment and model. Note that in this case the model describes very accurately the experimental evolution. The values of the parameters $a_{i}$ are given in Table 5. The left-hand term of Eq. (3) is given by:

$\phi\left(\frac{\partial S}{\partial P}\right)=-\frac{M}{\rho R T} \phi \sum_{k=1}^{6} k a_{k} \exp \left(-k \frac{M P}{\rho R T}\right)$

The relative permeability was approximated using the abovementioned procedure. The resulting intrinsic permeability to water was found to be $3.9 \times 10^{-21} \mathrm{~m}^{2}$ (around twenty times higher than the value obtained the usual van Genuchten model).

\subsubsection{Pickett's model}

This model was proposed by Pickett [17]. It is an evolution of the BET model [3] which was designed to reproduce type IV isotherms representative of capillary condensation in mesoporous materials (representative of cementitious materials) [22]. It accounts for mono- and multi-molecular adsorption only (capillary condensation is ignored): this is of minor importance here since the equation is only used to fit the results (no information is

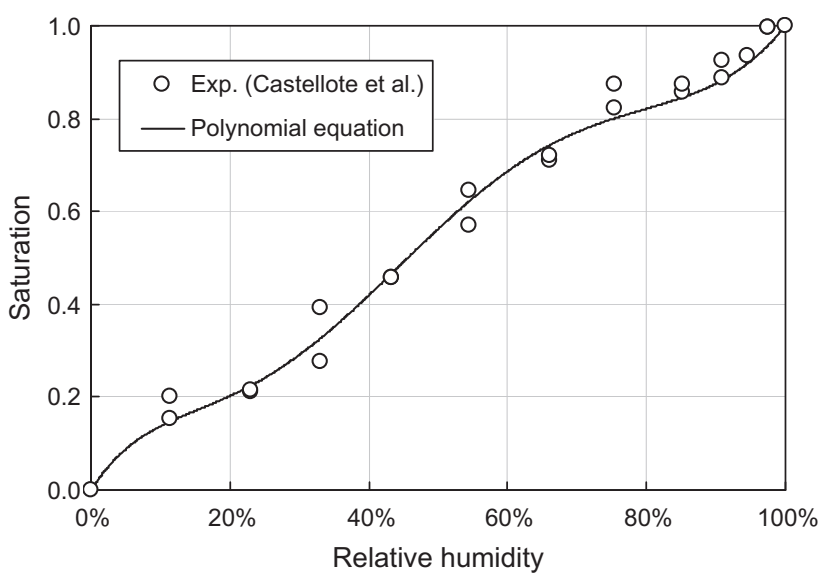

Fig. 11. Description of the experimental desorption isotherm using a polynomial equation. 
Table 5

Parameters for the polynomial expression.

\begin{tabular}{llllllll}
\hline Parameter & $a_{0}$ & $a_{1}$ & $a_{2}$ & $a_{3}$ & $a_{4}$ & $a_{5}$ & $a_{6}$ \\
\hline Value & 0.000 & 2.351 & -14.098 & 50.445 & -76.970 & 51.379 & -12.107 \\
\hline
\end{tabular}

deduced from its parameters). It can be written under the following form [17]:

$S(h)=C S_{m} \frac{h\left(1-h^{p}\right)+D p(1-h) h^{p}}{(1-h)\left[(1-h)+C\left(h+b h^{p}\right)\right]}$

where $C, S_{m}, D$ and $p$ are the four model parameters. $C$ is related to the adsorption energy in the first layer; it is positive. $S_{m}$ is the saturation needed to complete the monolayer (it is positive and less than unity); $D$ is a positive parameter and $p$ corresponds to the maximal number of layers which can be built (it is a positive integer but Pickett allowed it to be a real). The comparison between the model and the experimental results is presented in Fig. 12: note the good description. The model parameters are reported in Table 6.The left-hand term of the water-transport equation is not easy to derive due to the complexity of the function used for the isotherm: the derivative $\left(\frac{\partial S}{\partial P}\right)$ was then decomposed in two terms:

$\phi\left(\frac{\partial S}{\partial P}\right)=\phi\left(\frac{\partial S}{\partial h}\right)\left(\frac{\partial h}{\partial P}\right)$

The first derivative was obtained by differentiation of Eq. (21)

$$
\left\{\begin{array}{l}
\left(\frac{\partial S}{\partial h}\right)=\frac{S(h)}{1-h}+S(h) \frac{C\left(1+D p h^{p-1}\right)-1}{(1-h)+C\left(h+D h^{p}\right)}+C S_{m} \frac{1-h^{p}(1+p+D p)+D p^{2}(1-h) h^{p-1}}{(1-h)\left[(1-h)+C\left(h+D h^{p}\right)\right]} \\
\text { with } h=\exp \left(-\frac{M P}{\rho R T}\right)
\end{array}\right.
$$

The second term was obtained by differentiation of Kelvin-Laplace equation (Eq. (4)):

$\left(\frac{\partial h}{\partial P}\right)=-\frac{M}{\rho R T} \exp \left(-\frac{M P}{\rho R T}\right)$

The relative permeability evolution was then approximated using the trapezoidal rule: the resulting intrinsic permeability was found to be $1.0 \times 10^{-21} \mathrm{~m}^{2}$ (around five times higher than the value obtained the usual van Genuchten model).

\section{Discussion}

The results of the different evaluation processes in terms of intrinsic permeability are presented in Table 7 . The values differ

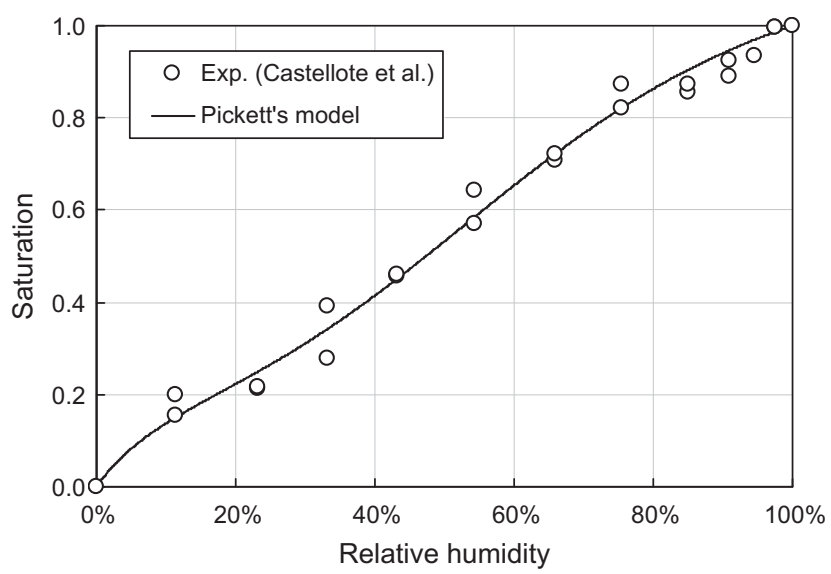

Fig. 12. Description of the experimental isotherm using the model proposed by Pickett [17].
Table 6

Parameters for Pickett's model.

\begin{tabular}{lllll}
\hline Parameter & $C$ & $S_{m}$ & $D$ & $p$ \\
\hline Value & 8.727 & 0.250 & 2.133 & 4 \\
\hline
\end{tabular}

depending on the model used for the isotherm description. The lower values were obtained using the two van Genuchten models $\left(2.1 \times 10^{-22}\right.$ and $2.7 \times 10^{-22} \mathrm{~m}^{2}$ for the usual and the three-parameter models respectively). The difference between the two permeability values is not significant in relation to the similitude of the two retention curves obtained.

Significantly higher values were obtained using the alternative isotherm models (namely Pickett, linear and polynomial expressions). The higher value was obtained using the polynomial expression $\left(3.9 \times 10^{-21} \mathrm{~m}^{2} ; 20\right.$ times greater than the value obtained using the usual van Genuchten model) followed by the linear expression $\left(2.0 \times 10^{-21} \mathrm{~m}^{2} ; 10\right.$ times greater than the value obtained using the usual van Genuchten model) and by Pickett's model $\left(1.0 \times 10^{-21} \mathrm{~m}^{2}\right.$; five times greater than the value obtained using the usual van Genuchten model). These results underline the important dependence of the intrinsic permeability evaluation approach to the model selected for the isotherm description.

One can then wonder how to apprehend these results: what is the concrete real intrinsic permeability? The answer can be found on Fig. 13 which presents the relative $\left(k_{r}\right)$ and effective permeability (the product $K \times k_{r}$ ) evolutions versus saturation for each isotherm model. One can see on (a) that the relative permeability evolutions greatly differ the ones from the others depending on the shape of the considered isotherm. The more the saturation fall at high $\mathrm{RH}$ in the desorption isotherm, the more the fall of permeability at high saturation. This is due to Mualem's model which implicitly assumes the existence of a large-radius pore population (which is de-saturated at high $\mathrm{RH}$ according to Kelvin's equation). Beyond the loss of the biggest contribution to the whole permeability, the drainage of this pore-population (at high saturation) also implies the partial depercolation of the interconnected porenetwork; this results in a sharp decrease of relative permeability.

(b) presents the effective permeability evolutions thus obtained: here the differences are only visible at high saturation (typically between 0.9 and 1.0). For saturations lower than 0.9 all the curves almost overlap. As a matter of fact, whatever the isotherm equation selected (and consequently the intrinsic permeability) the resulting effective permeability tends to describe the same curve. This evolution is believed to be representative of the unsaturated water transport property of the considered material. In this evaluation process the intrinsic permeability value is fixed to fit the effective permeability evolution. It is obviously model-dependent and then is to be apprehended carefully. Yet, the convergence of all the curves towards a unique effective permeability evolution is believed by the author to be an evidence of the robustness of the evaluation process. Whatever the chosen isotherm model, one can expect to obtain a result which is representative of the material intrinsic unsaturated transport property.

Table 7 also presents the value of the minimum of the objective function $F$ for each model and the time needed for each computation. It must noted that the deviation between the simulations and the experimental mass loss data for the alternative isotherm models (namely Pickett, linear and polynomial expressions) is lower than the ones exhibited by the two van Genuchten models. This point is not believed by the author to be really significant: much more results should be needed to confirm (or not) this fact.

The other point of interest is the time needed for the computations (the latter were performed using the same procedure and the same computer: Intel Q9400 CPU with 3.5 Go RAM). It is about 
Table 7

Comparison of the different permeability assessment approaches.

\begin{tabular}{|c|c|c|c|c|}
\hline Model & Parameters & Error $F$ & CPU time $(\mathrm{s})$ & Permeability $K\left(\mathrm{~m}^{2}\right)$ \\
\hline Usual van Genuchten & 2 & $1.0 \times 10^{-6}$ & 1070 & $2.1 \times 10^{-22}$ \\
\hline 3-Parameter van Genuchten & 3 & $7.3 \times 10^{-7}$ & 930 & $2.7 \times 10^{-22}$ \\
\hline Linear model & 2 & $3.7 \times 10^{-7}$ & 620 & $2.0 \times 10^{-21}$ \\
\hline Pickett's model & 4 & $1.8 \times 10^{-7}$ & 690 & $1.0 \times 10^{-21}$ \\
\hline Polynomial expression & 7 & $4.5 \times 10^{-7}$ & 650 & $3.9 \times 10^{-21}$ \\
\hline
\end{tabular}

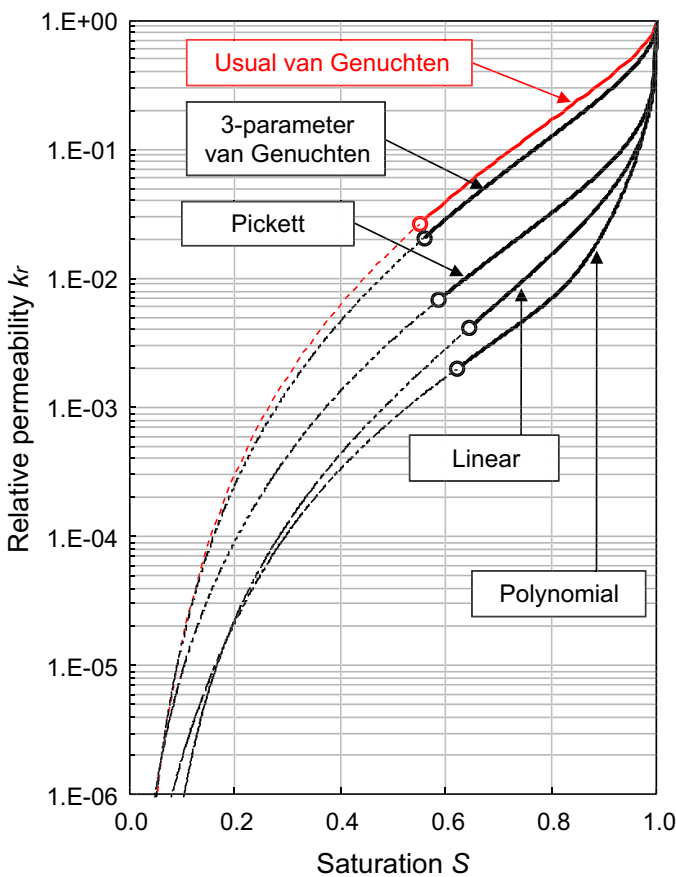

(a) Relative permeability

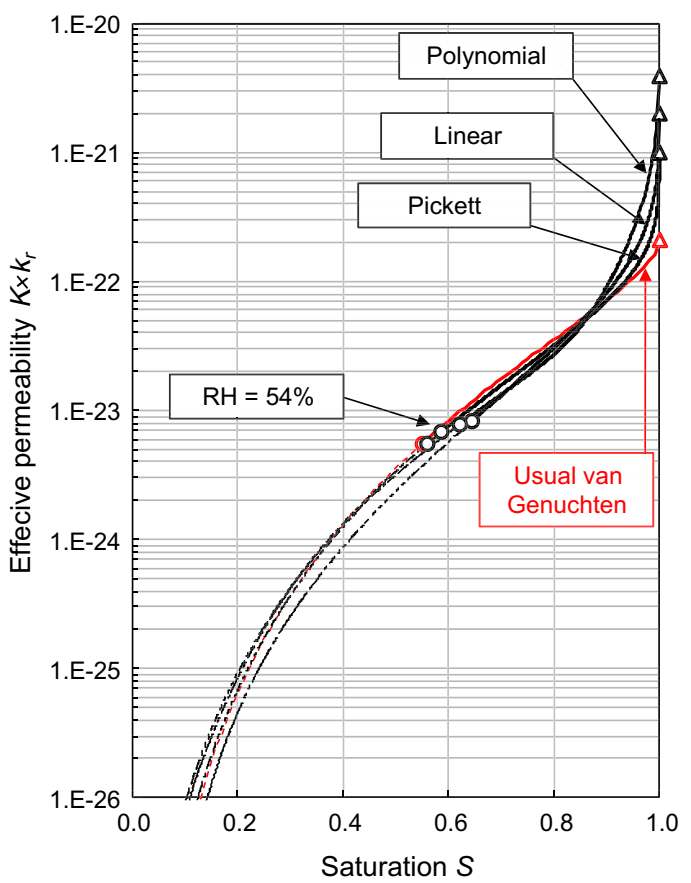

(b) Effective permeability

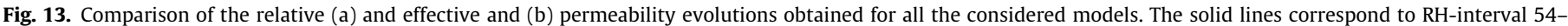
$100 \%$, whereas the dotted lines correspond to $0-54 \%$.

$1000 \mathrm{~s}$ for both van Genuchten models; it is significantly lower (600-700 s, about 30-40\% less) for all the other models considered in this study. The choice of alternative models to van Genuchten then offers two major advantages: the model can be chosen to obtain a better fit and the resulting calculation can be faster (at least for the three models tested in this study).

\section{Conclusion}

The intrinsic permeability is a key parameter for the description of water transport within concretes. It is generally evaluated through an inverse analysis by reprocessing concrete samples experimental weight variation in a controlled environment. To investigate the impact of the water retention curve model on the assessment process, an isothermal drying of concrete samples was conducted and the intrinsic permeability was evaluated. In a first step the relative permeability was classically estimated using the Mualem-van Genuchten model. Alternative estimations were also achieved using arbitrary functions (namely Pickett's model, linear and polynomial expressions) for which the relative permeability evolution was numerically approximated using the trapezoidal form of Riemann sums.

The results show that the intrinsic permeability spread from 2.1 to $39.0 \times 10^{-22} \mathrm{~m}^{2}$ depending of the considered water retention function and the resulting relative permeability evolution. This variation emphasizes the dependence of the intrinsic permeability evaluation process to the selected model. Yet all the effective permeability evolutions obtained in this study appear to converge towards a unique evolution which is representative of the concrete unsaturated permeability. This can be taken as an evidence of the robustness of the permeability assessment approach.

These results are important since they show that it is possible to choose any arbitrary mathematical function to describe the water retention curve (for instance to obtain a better fit than the one given by van Genuchten's equation). In so doing, the relative permeability (Mualem's model) can be approximated with confidence using simple numerical procedures such as the one proposed in this study (adapted from the trapezoidal form of Riemann sums). The time needed for the computations can also be significantly reduced.

\section{Acknowledgements}

This work could be done thanks to the financial support of the Belgian Agency for Radioactive Waste and Enriched Fissile Materials (ONDRAF/NIRAS). The author would like to thank H. van Humbeeck and R. Gens for their active participation.

\section{References}

[1] Baroghel-Bouny V, Mainguy M, Lassabatère T, Coussy O. Characterization and identification of equilibrium and transfer moisture properties for ordinary and high-performance cementitious materials. Cem Concr Res 1999;29(8): 225-1238 
[2] Baroghel-Bouny V. Water vapour sorption experiments on hardened cementitious materials. Part I: Essential tool for analysis of hygral behavior and its relation to pore structure. Cem Concr Res 2007;37(3):414-37.

[3] Brunauer S, Emmett PH, Teller E. Adsorption of gases in multimolecular layers. J Am Chem Soc 1938;60(2):309-19.

[4] Castellote Armero M, Andrade Perdrix C, Castillo Talavera A. Characterization and properties of cementitious matrices for a surface disposal of LLW. Institute Eduardo Torroja (IeTcc) Report 19.171, 98; 2009.

[5] Coussy O. Poromechanics. England: John Wiley and Sons; 2004. 298p.

[6] Davis PJ. Gamma functions and related functions. In: Abramowitz, Stegun editors. Handbook of mathematical functions with formulas, graphs and mathematical tables. Dover Publications; 1972. p. 1046p.

[7] Gawin D, Schrefler BA. Thermo-hydro-mechanical analysis of partially saturated porous materials. Eng Comput 1996;13(7):113-43.

[8] Hover KC. The influence of water on the performance of concrete. Constr Build Mater 2011;25(7):3003-13.

[9] Khatib JM, Mangat PS. Absorption characteristics of concrete as a function of location relative to the casting position. Cem Concr Res 1995;25(5):999-1010.

[10] Khatib JM, Mangat PS. Porosity of cement paste cured at $45^{\circ} \mathrm{C}$ as a function of location relative to casting position. Cem Concr Compos 2003;25(1):97-108.

[11] Khatib JM, Kenai S, Zhang JS, Firat S, Harris PH. Effect of sample location and curing on pore volume and threshold diameter of cement paste with and without slag. In: Zachar et al. editors, Proceedings of the 2nd international conference on sustainable construction materials and technologies, Ancona, Italy, 28-30 June 2010.

[12] Kreijger PC. The skin of concrete composition and properties. Mater Struct 1990;17(2):275-83

[13] Mainguy M, Coussy O, Baroghel-Bouny V. Role of air pressure in drying of weakly permeable materials. ASCE J Eng Mech 2001;127(6):582-92.

[14] Meftah F, Dal Pont S. Staggered finite volume modeling of transport phenomena in porous materials with convective boundary conditions. Transp Porous Media 2010;82(2):275-98.

[15] Mualem Y. A new model for predicting the hydraulic conductivity of unsaturated porous media. Water Resour Res 1976;12(3):513-22.
[16] Ondraf-Niras. The cAt project in dessel, a long-term solution for Belgian category A waste. Report Nirond 2010-02 E, March 2010. 139p <http:// www.niras-cat.be/downloads/cAt_masterplanENG.pdf >.

[17] Pickett G. Modification of the Brunauer-Emmett-Teller theory of multimolecular adsorption. J Am Chem Soc 1945;67(11):958-1962.

[18] Powers TC, Brownyard TL. Physical properties of hardened Portland cement paste. Part 2: Studies of water fixation. J Am Concr Inst Proc 1946;43(9):249-336

[19] Richards LA. Capillary conduction of liquids through porous mediums. Physics 1931;1(5):318-33.

[20] Savage BM, Janssen DJ. Soil physics principles validated for use in predicting unsaturated moisture movement in Portland cement concrete. ACI Mater J 1997;94(1):63-70.

[21] Šelih J, Sousa ACM, Bremner TW. Moisture transport in initially fully saturated concrete during drying. Transp Porous Media 1996;24(1):81-106.

[22] Sing KSW, Everett DH, Haul RAW, Moscou L, Pierotti RA, Rouquérol J, et al. Reporting physisorption data for gas/solid systems with special reference to the determination of surface area and porosity. Pure Appl Chem 1985;57(4):603-19.

[23] Thiery M, Baroghel-Bouny V, Bourneton N, Villain G, Stéfani C. Modélisation du séchage des bétons, analyse des différents modes de transfert hydrique (in French). Eur J Environ Civ Eng 2007;11(5):541-77.

[24] Thiery M, Belin P, Baroghel-Bouny V, Nguyen M. Modeling of isothermal drying process in cementitious materials: analysis of the moisture transfer and proposal of simplified approaches. In: Shao, Burlion, editors. Proceedings of the 3rd symposium GeoProc. Lille, France: Wiley; 2008. p. 571-9.

[25] Tuutti K. Corrosion of steel in concrete. Report CBI 10/4/1982 (ISSN 03466906). Swedish Cement and Concrete Research Institute; 1982. 468p.

[26] Van Genuchten MT. A closed-form equation for predicting the hydraulic conductivity of unsaturated soils. Soil Sci Soc Am J 1980;44(5):892-8.

[27] Van Genuchten MT, Nielsen DR. On describing and predicting the hydraulic properties of unsaturated soils. Ann Geophys 1985;3(5):615-28.

[28] Zienkiewicz OC, Taylor RL. The finite element method. The basis, vol. 1. Oxford (UK): Butterworth-Heinemann; 2000. 